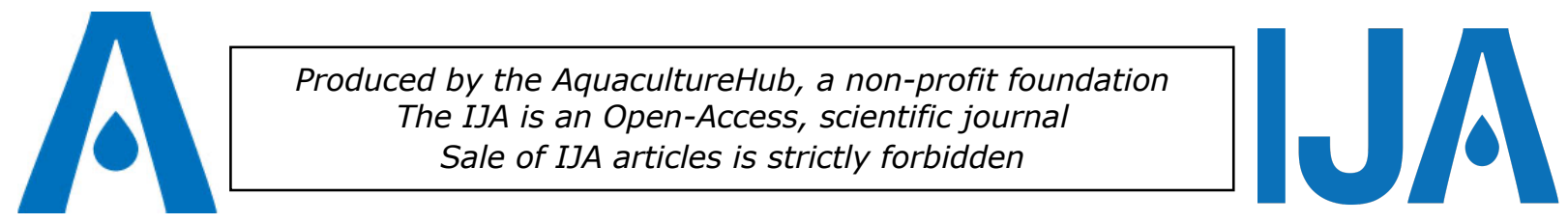

\title{
Dietary bile acids supplementation improves the growth performance with regulation of serum biochemical parameters and intestinal microbiota of growth retarded European eels (Anguilla anguilla) cultured in cement tanks
}

\author{
Shao-Wei Zhai*, Pan-Yue Zhao, Lin-Xin Huang
}

\author{
Fisheries College of Jimei University, Engineering Research Center of the \\ Modern Industry Technology for Eel, Ministry of Education, China
}

\begin{abstract}
Key words: Bile acids, growth retarded European eel, intestinal microbiota, cement tanks
\end{abstract}

\begin{abstract}
The present trial was conducted to investigate the effects of bile acids on growth performance, digestive enzymes activities, serum biochemical parameters and intestinal microbiota on growth of retarded European eels (Anguilla anguilla) cultured in cement tanks. The trial fish with similar body size (about $140 \mathrm{~g}$ per fish) cultured in nine cement tanks (fish weight, $681.7 \pm 22.7 \mathrm{~kg}$ per tank) were randomly divided into three groups and fed diets with bile acids supplementation at a level of 0,500 , and $1000 \mathrm{mg} / \mathrm{kg}$, respectively. The trial period was 15 weeks. Dietary bile acids supplementation improved weight gain rate, feed intake, and activities of protease and lipase in intestine. There were also increases in levels of immunoglobulin and complements as well as activities of alkaline phosphatase (only in 1000 $\mathrm{mg} / \mathrm{kg}$ bile acids group), acid phosphatase and lysozyme in serum. The levels of blood urea nitrogen, total cholesterol, triglyceride, low density lipoprotein cholesterol and activities of glutamic-oxalacetic transaminase and glutamic-pyruvic transaminase were decreased by dietary bile acids supplementation. There were no significant differences in growth performance or serum biochemical parameters except the lysozyme activity between two bile acids supplementation groups. Dietary bile acids supplementation could increase richness and decrease diversity of the intestinal microbiota with different enriched bacteria at genus level. In conclusion, this study demonstrated that $500 \mathrm{mg} / \mathrm{kg}$ bile acids supplementation in the diet of growth retarded European eels cultured in cement tanks could promote growth performance, improve some digestive enzymes activities, and beneficially regulate serum biochemical parameters and intestinal microbiota.
\end{abstract}

\footnotetext{
* Corresponding author. e-mail: shaoweizhai@hotmail.com
} 


\section{Introduction}

Eel is one of the fish species with high-value market for freshwater aquaculture in the world. European eel (Anguilla anguilla) is an important eel species cultured in China, which was listed on Appendix II of the IUCN as a Critically Endangered Species (Jacoby et al., 2015). Appendix II lists species that are not necessarily threatened with extinction at present. International trading in Appendix II species may be authorized by the granting of an export permit or reexport certificate if the relevant authorities are satisfied that trade will not be detrimental to the survival of the species in the wild (Nijman, 2017). Therefore, there are still limited quantities of Anguilla anguilla glass eels imported into China every year. European eels are usually farmed in cement tanks in China. During the culture process, growth retarded eels account about $30 \%$ of the total population, which is the highest among all cultured eel species. Those retarded fish have small body size and low feed intake with a very slow growth rate, some fish may eat little feed with nearly no weight gain. This phenomenon might be caused by mismanagement of starter feeding, detrimental environment, and diseases, which led to heavy economic losses for eel industry (Huang, 2012; Zhai et al., 2016). The previous studies related to growth retarded eels showed that the improvements of digestive enzymes activities and health status in intestine could promote their growth performance (Zhai et al., 2016,2017).

Bile acids (BA) are a series of sterols synthesized from cholesterol metabolism in the liver, stored in the gallbladder, and released after feeding into the small intestine. Within the small intestine, BA act as effective detergents and play the remarkable function of facilitating the solubilization of monoacylglycerols and fatty acids, and the digestion and absorption of dietary lipids and fat-soluble vitamins (Di Ciaula et al., 2017; Ramírez-Pére et al., 2017; Kiriyama and Nochi, 2019). BA also play key roles as signaling molecules in modulating epithelial cell proliferation, gene expression, lipid and glucose metabolism (Di Ciaula et al., 2017).

The functions of BA as a feed additive have been investigated in many fish species. Previous studies demonstrated that BA could improve growth performance of some fish species, which have been confirmed in cobia (Rachycentron canadum) (Zhou et al., 2010), grass carp (Ctenopharyngodon idella) (Zhou et al., 2018), snakehead (Channa argus)(Hou et al., 2019) , turbot (Scophthalmus Maximus) (Sun et al., 2014), and Ya-fish (Schizothorax prenanti) (Zheng et al., 2016, Xiang et al., 2019). Recently, some studies reported that the functions of BA in alleviating the negative effects on growth performance and metabolism of some fish species under nutritional stress. BA could to improve the growth performance by regulating lipid homeostasis in liver of black seabream (Acanthopagrus schlegelii), grass carp, rainbow (Oncorhynchus mykiss), and large yellow croaker (Larimichthys crocea) fed high-fat diets (Adhami et al., 2017; Zhou et al., 2018; Jin et al., 2019; Ding et al., 2020). Similar effects of dietary BA supplementation were found in grass carp fed low-protein diet (Peng et al., 2019), largemouth bass (Micropterus salmoides) fed high-starch diet (Yu et al., 2019; Guo et al., 2020), large yellow croaker (Larimichthys crocea) fed diets with high replacement of fish oil with soybean oil (Du et al., 2017), and rainbow trout fed diets with high non-starch polysaccharides (Staessen et al., 2020). In addition, BA has been reported to attenuate the changes in growth performance and lipid metabolism of rainbow trout (Oncorhynchus mykiss), tilapia (Oreochromis niloticus), and turbot fed plant ingredient-based diets (Yamamoto et al., 2007; Gu et al., 2017; Jiang et al., 2018). In these studies, the growth performances of those fish species were improved with amelioration of digestive enzymes activities and intestinal health status by adequate BA supplementation in the fish diets. It is important to investigate the effects of BA supplementation in growth retarded European eels under practical culture condition. Therefore, this experiment was conducted to study the effects of dietary BA on growth performance, activity of intestinal digestive enzymes, serum biochemical parameters and intestinal microbiota of growth retarded European eels cultured in cement tanks.

\section{Feeding experiment}

\section{Materials and Methods}

The European eels cultured for two and half years were farmed in Hexagon cement tanks (30 $\mathrm{m}^{2}$ with $150 \mathrm{~cm}$ height and $90 \mathrm{~cm}$ water depth) with water recirculation system in a commercial farm (Jinjiangzhiman Aquatic technology Co., Ltd., Zhangzhou, China). The commercial powder 
diet contained $47.43 \%$ crude protein, $4.81 \%$ lipids, $16.87 \%$ ash, 4.16 calcium, $2.85 \%$ total phosphorus (provide by Zhejiang Kesheng Feed Co., Ltd., Shaoxing, China). The proximate composition of the commercial diet was $47.43 \%$ crude protein, $4.81 \%$ crude lipid, moisture $6.08 \%$, calcium $4.16 \%$, total phosphorus $2.85 \%$, ash $11.15 \%$. The commercial powder diet was mixed with water 1.2 times the diet weight to form dough. The dough was placed on a feeding table and served to the eels of each tank, and the fish were fed to apparent satiation twice daily (at 6:00 $\mathrm{h}$ and 18:00 h), any uneaten feed was collected $0.5 \mathrm{~h}$ after feeding and dried. The total amount of daily consumed feed was calculated by subtracting uneaten feed from the feeding diet. The speed of water flow in cement tanks was $0.4 \mathrm{~L} / \mathrm{min}$. The water temperature was kept at $26-30{ }^{\circ} \mathrm{C}$. Levels of dissolved oxygen, $\mathrm{pH}$ and ammonia were maintained at $10-15 \mathrm{mg} / \mathrm{L}, 6.0-6.5$ and $8.0-8.5 \mathrm{mg} / \mathrm{L}$, respectively. Water quality was monitored twice a week with a multiparameter photome (HI9804N, HANNA, Baranzate, MI, Italy). The dead fish were recorded and weighted daily.

After grading eels from 30 cement tanks of this farm to culture similar body size fish in each tank, trial fish with similar body weight (140g per fish) in nine tanks $(681.7 \pm 22.7 \mathrm{~kg}$ per tank) were chosen as the trial fish. The nine tanks were randomly divided into three groups fed diets with BA (contained 55\% total BA, Xiamen Xingmuwei Animal Health Product Co., Ltd, Xiamen, China) supplementation level being 0,500, and $1000 \mathrm{mg} / \mathrm{kg}$, respectively. The trial lasted for 15 weeks. The same basal diet and culture management were maintained in adaption and trial period. Fish and water managements of tanks for trial were the same with other tanks of this commercial eel farm.

Sample collection

At the end of the feeding trial, all fish were fasted for $24 \mathrm{~h}$ prior to final sampling. Fish in each tank were weighted. Nine fish from each tank were sampled at random and anaesthetized with $2 \mathrm{~g} / \mathrm{L}$ eugenol. Blood from six fish per tank was obtained by puncturing the caudal vein using a $2 \mathrm{ml}$ syringe. Blood samples were allowed to clot at $4^{\circ} \mathrm{C}$ for $12 \mathrm{~h}$ and then centrifuged $\left(3000 \mathrm{r} / \mathrm{min}, 4^{\circ} \mathrm{C}\right)$ for 10 mins to collect serum samples. After the fish were killed in an ice bath, the intestines were separated and immediately collected in centrifuge tubes, the intestine from the same tank were then pooled and homogenized in 10 volumes $(\mathrm{v} / \mathrm{w})$ of ice-cold normal saline $(0.68 \%)$. The homogenates were centrifuged at $3000 \mathrm{r} / \mathrm{min}$ for $15 \mathrm{~min}$ at $4{ }^{\circ} \mathrm{C}$ and the supernatants were collected. The intestines of three fish were collected in centrifuge tubes for measuring microbiota diversity. Samples of serum and intestine were stored at $-80^{\circ} \mathrm{C}$ for further analyses.

Analytical procedures

Intestinal digestive enzymes. Total protease activity was measured by method of casein hydrolysis. Amylase activity and Lipase activity were measured by method of commercial kits (Nanjing Jiancheng Biotechnic Institute, China) (Zhai et al., 2016).

Serum biochemical parameters. The commercial clinical investigation kits (Nanjing Jiancheng Bioengineering Institute, Nanjing, China) were used to determine levels of blood urea nitrogen (BUN), total cholesterol (TC), triglyceride (TG), high density lipoprotein cholesterol (HDL-C), low density lipoprotein cholesterol (LDL-C), immunoglobulin M (IgM) and complements C3 and the activities of glutamic-oxalacetic transaminase (GOT)and glutamicpyruvic transaminase (GPT), acid phosphatase (AKP), alkaline phosphatase (ACP), and lysozyme (LZM) in the serum according to the manufacturer's protocol.

Intestinal microbiota analysis. Four intestine samples of each group were used to 16S rDNA identification. The whole processes of pyrosequencing and preparation including extraction and amplification of total genomic DNA of intestine were assisted by the Beijing Allwegene Technology Co., Ltd. (Beijing, China). The 16S rDNA identification was carried out with the Illumina MiSeq PE300 platform, the processes of sequencing and raw data treatment were same with the study conducted by Shi et al. (2020).

Growth performance calculation

At the end of the trial, fish weight was measured in each tank after $24 \mathrm{~h}$ of feed deprivation. The sum of this fish weight and dead fish weight of each tank was considered as the final fish weight (FFW) to calculate the following growth performance parameters. Weight gain rate (WGR), feeding rate (FR), feed conversion ratio (FCR), and survival rate (SR) were calculated as follows:

The Israeli Journal of Aquaculture - Bamidgeh • IJA.72.2020.1217104 
WGR $(\%)=[$ final fish weight $(\mathrm{kg} /$ tank $)$ - initial fish weight $(\mathrm{kg} /$ tank $)] /$ initial fish weight $(\mathrm{kg} / \operatorname{tank}) \times 100 \%$.

$\mathrm{FR}(\%)=$ feed consumption $(\mathrm{kg} /$ tank $) /$ average fish weight of fish $(\mathrm{kg} / \operatorname{tank}) \times 100 \%$.

$\mathrm{FCR}=$ feed intake $(\mathrm{kg} /$ tank $) /[$ final fish weight $(\mathrm{kg} /$ tank $)$ - initial fish weight $(\mathrm{kg} /$ tank $)]$.

SR $(\%)=$ (initial number of fish per tank - total number of dead fish per tank) / initial number per tank $\times 100 \%$. The initial number of fish per tank was estimated with the value of initial fish weight per tank divided by initial weight per fish.

Statistical Analyses

The results are presented as means \pm SD. Data expressed as percentages or ratios were $S$ arcsine-square-root-transformed before statistical analyses. All data checked for normality (K olmogorov-Smirnov test) and homoscedasticity of variance (Bartlett's test). Data on growth $\mathrm{p}$ erformance, serum biochemical parameters and alpha diversity indexes of the intestinal micro biota were subjected to one-way ANOVA followed by the Duncan's multiple-range test to dete rmine significant differences among three treatment groups using SPSS 22.0 (SPSS Inc., Chic ago, IL, USA). When overall differences were significant $(P<0.05)$, Duncan's multiple range te st was used to compare the mean values among different treatment groups. The Chao1 and $S$ hannon diversity parameters of all samples were calculated with the vegan package (https:// www.rdocumentation.org/packages/vegan/versions/2.4-2) in R programming for determining bacterial diversity. Linear discriminant analysis (LDA) effect size (LEfSe) method was perform ed on the Galaxy web-based interface (http://huttenhower.sph.harvard.edu/galaxy) to detect ing the differential bacteria in intestine of European eels from different groups. LEfSe analysis was identified by LDA value $>3$ and $P<0.05$.

\section{Growth performance}

\section{Results}

The effects of BA supplementation on growth performance of growth retarded European eels are shown in Table 1. Compared with the control group, WGR and FI of BA groups were significantly increased, $(P<0.05)$. FR, FCR, and SR were not affected significantly $(P>0.05)$. There were no significant differences of all growth parameters between BA groups $(P>0.05)$.

Table 1 Growth performance of growth retarded European eels fed diets with different BA supplementation levels.

\begin{tabular}{lccc}
\hline Items & Control group & BA group I & BA group II \\
\hline IFW (kg/tank) & $683.0 \pm 21.5$ & $692.7 \pm 24.8$ & $669.0 \pm 23.6$ \\
FFW (kg/tank) & $901.0 \pm 60.4$ & $983.5 \pm 9.1$ & $946.1 \pm 34.1$ \\
WGR (\%) & $31.77 \pm 2.75^{\mathrm{a}}$ & $42.14 \pm 3.52^{\mathrm{b}}$ & $41.43 \pm 1.68^{\mathrm{b}}$ \\
FI (kg/tank) & $571.6 \pm 18.8^{\mathrm{a}}$ & $626.3 \pm 8.8^{\mathrm{b}}$ & $621.7 \pm 10.5^{\mathrm{b}}$ \\
FR (\%) & $0.66 \pm 0.02$ & $0.68 \pm 0.01$ & $0.70 \pm 0.02$ \\
FCR & $2.67 \pm 0.22$ & $2.17 \pm 0.12$ & $2.25 \pm 0.07$ \\
SR (\%) & $99.90 \pm 0.03$ & $99.84 \pm 0.05$ & $99.82 \pm 0.07$ \\
\hline
\end{tabular}

${ }^{a b}$ Values (means $\pm S D, n=3$ ) with different superscripts in the same row are significantly different $(P<0.05)$. $\mathrm{IFW}=$ initial fish weight, $F F W=$ final fish weight, $\mathrm{WGR}=$ weight gain rate, $F I=$ feed intake, $F C R=$ feed conversion ratio, $\mathrm{SR}=$ survival rate.

Digestive enzymes activities

Digestive enzymes activities in intestine of growth retarded European eels are shown in Table 2. Compared with the control group, activities of protease and lipase of BA groups were significantly increased $(P<0.05)$, amylase activity were not affected significantly $(P>0.05)$. 
Table 2 Digestive enzymes activities in intestinal tract of growth retarded European eels fed diets with different BA supplementation levels.

\begin{tabular}{lccc}
\hline Items & Control group & BA group I & BA group II \\
\hline Amylase (U/mg prot) & $0.32 \pm 0.06$ & $0.31 \pm 0.09$ & $0.32 \pm 0.02$ \\
Protease (U/mg prot) & $40.80 \pm 3.79^{\mathrm{a}}$ & $52.80 \pm 2.88^{\mathrm{b}}$ & $53.12 \pm 3.52^{\mathrm{b}}$ \\
Lipase (U/g prot) & $17.00 \pm 1.73^{\mathrm{a}}$ & $20.76 \pm 0.71^{\mathrm{b}}$ & $21.93 \pm 0.71^{\mathrm{b}}$ \\
\hline
\end{tabular}

${ }^{a b}$ Values (means $\pm S D, n=3$ ) with different superscripts in the same row are significantly different $(P<0.05)$.

\section{Serum biochemical parameters}

Serum biochemical parameters of growth retarded European eels are shown in Table 3. Compared with the control group, levels of BUN, TC, TG, LDL-C and activities of GOT and GPT of BA groups were significantly decreased $(P<0.05)$, levels of IgM and C3 and activities of AKP (only in BA group II), ACP and LZM were significantly increased $(P<0.05)$. There were no significant differences of above serum biochemical parameters (except LZM activity) between BA group I and BA group II ( $P>0.05)$.

Table 3 Serum biochemical parameters of growth retarded European eel fed diets with different BA supplementation levels.

\begin{tabular}{|c|c|c|c|}
\hline Items & Control group & BA group I & BA group II \\
\hline BUN (mmol /L) & $9.86 \pm 0.01^{b}$ & $8.57 \pm 0.27^{a}$ & $8.52 \pm 0.27^{a}$ \\
\hline $\mathrm{TC}(\mathrm{mmol} / \mathrm{L})$ & $21.47 \pm 0.46^{b}$ & $19.69 \pm 0.52^{a}$ & $19.05 \pm 0.41^{a}$ \\
\hline TG $(\mathrm{mmol} / \mathrm{L})$ & $11.96 \pm 0.45^{\mathrm{b}}$ & $10.35 \pm 0.16^{\mathrm{a}}$ & $10.47 \pm 0.28^{\mathrm{a}}$ \\
\hline $\mathrm{HDL}-\mathrm{C}(\mathrm{mmol} / \mathrm{L})$ & $8.09 \pm 0.60$ & $8.50 \pm 1.22$ & $9.82 \pm 0.37$ \\
\hline LDL-C (mmol/L) & $8.72 \pm 0.06^{b}$ & $7.22 \pm 0.38^{\mathrm{a}}$ & $6.28 \pm 0.57^{a}$ \\
\hline GOT (U/L) & $12.48 \pm 0.72^{b}$ & $9.46 \pm 0.24^{a}$ & $9.15 \pm 0.92^{\mathrm{a}}$ \\
\hline GPT (U/L) & $58.57 \pm 2.43^{b}$ & $40.15 \pm 2.36^{a}$ & $43.79 \pm 2.39^{a}$ \\
\hline $\operatorname{IgM}(\mathrm{ug} / \mathrm{mL})$ & $32.78 \pm 3.79^{a}$ & $54.38 \pm 8.40^{\mathrm{b}}$ & $55.85 \pm 3.67^{b}$ \\
\hline C3 (ug/mL) & $777.78 \pm 24.39^{a}$ & $855.75 \pm 12.80^{b}$ & $880.84 \pm 29.42^{b}$ \\
\hline $\mathrm{ACP}(\mathrm{U} / \mathrm{L})$ & $14.07 \pm 1.14^{\mathrm{a}}$ & $19.92 \pm 0.86^{b}$ & $18.85 \pm 2.28^{\mathrm{b}}$ \\
\hline AKP $(U / L)$ & $6.00 \pm 0.36^{a}$ & $7.14 \pm 0.21^{\mathrm{ab}}$ & $8.50 \pm 0.79^{b}$ \\
\hline LZM (U/mL) & $0.80 \pm 0.11^{a}$ & $2.32 \pm 0.01^{c}$ & $1.68 \pm 0.07^{b}$ \\
\hline
\end{tabular}

${ }^{a b}$ Values (means $\pm S D, n=3$ ) with different superscripts in the same row are significantly different $(P<0.05)$. $\mathrm{BUN}=$ blood urea nitrogen, $\mathrm{TC}=$ total cholesterol, $\mathrm{TG}=$ triglyceride, $\mathrm{HDL}-\mathrm{C}=$ highdensity lipoproteincholesterol, $\mathrm{LDL}-\mathrm{C}=$ Low density lipoprotein cholesterol, GOT= glutamic-oxalacetic transaminease, GPT= glutamic-pyruvic transaminase, IgM= Immunoglobulin $\mathrm{M}, \mathrm{C} 3=$ complement 3, AKP= alkaline phosphatase, $\mathrm{ACP}=$ acid phosphatase, LZM= lysozyme.

\section{Change of intestinal microbiota}

The diversity indexes of intestinal microbiota are shown in Table $4 . \quad$ More OTUs were obtained from intestinal samples of growth retarded European eels fed diets with BA supplementation. The value of the Chao1 index was significantly higher in the BA group in comparison with the control group $(P<0.05)$, and there was no significant difference between the BA group I and the BA group II $(P>0.05)$. The value of the Shannon index was decreased significantly in the BA group I in comparison with the control group $(P<0.05)$, and there were no significant differences of BA group II compared with control group and BA group I $(P>0.05)$. The differences of coverage values were not significant among all the three groups $(P>0.05)$. 
Table 4 The diversity index of intestinal microbiota of growth retarded European eels fed diets with different BA supplementation levels.

\begin{tabular}{lccc}
\hline Items & Control group & BA group I & BA group II \\
\hline OUT number & 218 & 323 & 453 \\
Chao1 index & $132.61 \pm 7.10^{\mathrm{a}}$ & $255.64 \pm 13.21^{\mathrm{b}}$ & $228.61 \pm 16.03^{\mathrm{b}}$ \\
Shannon index & $3.57 \pm 0.64^{\mathrm{b}}$ & $1.84 \pm 0.32^{\mathrm{a}}$ & $2.06 \pm 0.39^{\mathrm{y}}$ \\
Coverage rate & 0.998 & 0.997 & 0.997 \\
\hline
\end{tabular}

${ }^{a b}$ Values (means $\pm S D, n=3$ ) with different superscripts in the same row are significantly different $(P<0.05)$.

The differential bacteria of growth retarded European eel from different groups are shown in Figure 1. At genus level, some bacteria from Microbacteriaceae family was enriched in control group. The Plesiomonas, Edwardsiella, Macellibacteroides, Clostridium_sensu_stricto_1 and Lachnospiraceae_NK4A136_group were enriched in BA group I, and Escherichia_Shigella was enriched in BA group II.

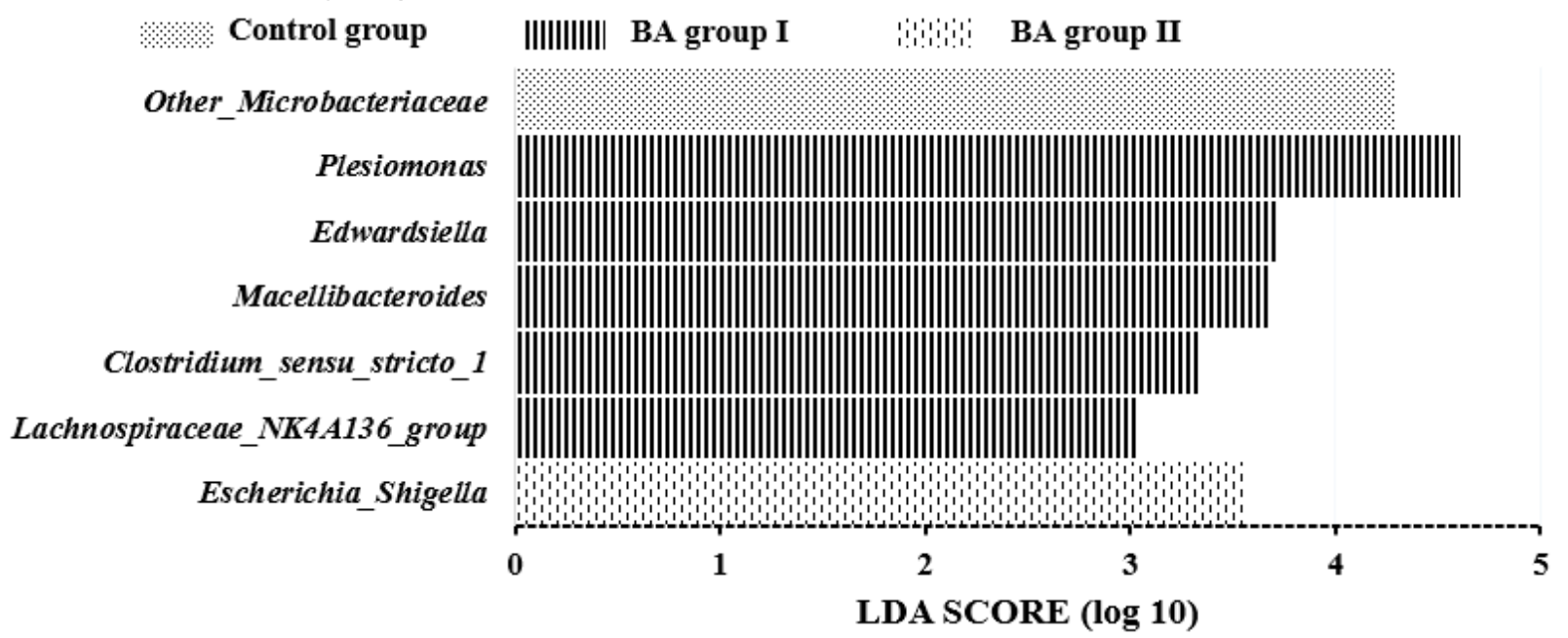

Figure 1 The differential bacteria Identified by LEfSe analysis of growth retarded European eel fed diets with different BA supplementation levels. The length of histogram represented the influence of significantly differential bacteria among three groups.

\section{Discussion}

The present study clearly demonstrated that both $500 \mathrm{mg} / \mathrm{kg}$ and $1000 \mathrm{mg} / \mathrm{kg} \mathrm{BA}$ supplementations in the diet enhanced the growth performance (including WGR, SGR and FI) of growth retarded European eels. These results were consistent with many previous reports, the optimal levels based on WGR or SGR of BA promoting growth effects were $60 \mathrm{mg} / \mathrm{kg}$ in grass carp fed high lipid diet (Zhou et al., 2018), $150 \mathrm{mg} / \mathrm{kg}$ in tilapia fed plant ingredientbased diets (Jiang et al., 2018), $150 \mathrm{mg} / \mathrm{kg}$ in turbot (Sun et al., 2014) and Ya-fish (Xiang et al., 2019), $169 \mathrm{mg} / \mathrm{kg}$ in grass carp fed the low-protein and high-lipid diet(Peng et al., 2019), $188 \mathrm{mg} / \mathrm{kg}$ in Ya-fish (Zheng et al., 2016), $300 \mathrm{mg} / \mathrm{kg}$ in Snakehead (Hou et al., 2019), 350 $\mathrm{mg} / \mathrm{kg}$ in largemouth bass fed high starch $\operatorname{diet}(\mathrm{Guo}$ et al., 2020), 475mg/kg in largemouth bass fed high starch diet(Yu et al., 2019). and $1500 \mathrm{mg} / \mathrm{kg}$ in rainbow trout fed a soybean mealbased diet (Yamamoto et al., 2007). However, based on the results of previous studies, it was found that the beneficial role of BA on growth of fish was dose dependent. Jin et al (2019) reported that dietary $200 \mathrm{mg} / \mathrm{kg}$ BA supplementation had no significant impact on growth performance of juvenile black seabream fed high-fat diet. Jiang et al. (2018) found that tilapia fed the BA at a level of $1350 \mathrm{mg} / \mathrm{kg}$ diet exhibited significant deleterious symptoms, similar results were also shown in on-growing grass carp fed high levels of exogenous $320 \mathrm{mg} / \mathrm{kg} B A$ supplementation decreasing growth performance and intestinal immunity (Peng et al., 2019). We concluded that the no promotion effects on growth performance of fish that ingested high levels of exogenous BA might be partly related to its adverse effects on enterohepatic 
circulation of BA, accumulation of cholesterol, cytotoxicity to hepatocytes (Jiang et al., 2018; Peng et al.,2019). In fact, most studies showed that BA could play important roles in promoting growth performance in many fish species, the dietary BA supplementation in different fish species may have diverse results. Even the same species may yield different results. Therefore, the required optimal level of supplemental BA or the capacity of these compounds may vary depending on the level and type of BA used, species of fish, feed formulation (levels and sources of dietary starch, lipid and protein), and other culture conditions (Jiang et al., 2018). It was concluded from the results of previous studies that the BA supplementation level in diets of European eel had no negative effects on growth performance, the optimal BA level should be confirmed in further research. In the present study, supplementation with BA did not affect physical indicators, meaning there were no significant differences in fish body size or development, which was similar to some other studies in black seabream (Jin et al., 2019), grass carp (Zhou et al., 2018), largemouth bass(Yu et al., 2019), large yellow croaker (Du et al., 2017), and snakehead (Hou et al., 2019). While Jiang et al. (2018) found that BA supplementation significantly affected the physical indicators of tilapia, this may be due to the differences of fish species, dietary composition, and nutrient levels. In European eel culture, it is usually found that a majority of the retarded fish are males. The growth rate of male eels is slower than female eels, and they reach a smaller size than females. We did not determine the sex proportion of trial fish, the different proportion of males to females might also affect the results in present study.

In agreement with other studies, adequate BA supplementation resulted in higher activities of lipase or protease in intestine as described in grass carp (Zhou et al.,2018), Japanese eel (Anguilla japonica) (Maita et al., 1996), tilapia (Jiang et al., 2018), turbot (Sun et al., 2014), Ya-fish (Zheng et al., 2016, Xiang et al., 2019). In the study of snakehead fed $300 \mathrm{mg} / \mathrm{kg} \mathrm{BA}$ in the diet, the activities of digestive enzymes were changed, which may be due to the differences of dietary BA levels and fish species (Hou et al., 2019). The enhancement of lipase activity could improve lipid digestion and the emulsification of lipidic compounds, as well as solubilizing them and enhancing lipid transport and absorption (Mukhopadhyay and Maitra, 2004; Romański, 2007). The mentioned beneficial effects of BA on lipase activity, as well as on lipid transport and absorption, might result in a better growth performance in the above fish species. The growth-promotion effect of exogenous BA could be attributed to the increased nutrients utilization efficiency and intestinal digestive enzyme activities. Besides, BA inclusion also significantly enhanced the feed intake, which contributed to the promoted growth as well. BA functioned as chemical signals and played an important role in promoting feed ingestion (Buchinger et al., 2014) because of the high sensitivity of the olfactory neurons of fish to BA (Zhang and Hara, 2009).

BUN is one of the final products of the protein metabolism in vivo, which can be used to determine the storage of nitrogen. The change in serum BUN concentrations reflects the whole body status of amino acid metabolism and utilization in fish (Hou et al., 2019), and decrease of BUN concentration of BA supplementation groups might suggest a potential enhancement of synthesis of protein in European eel. Compared to control group, the levels of TC, TG and LDL$C$ were noticeably lowered in the fish fed diets containing $B A$, and there was an increasing trend of HDL-C level of BA supplementation groups. Similar blood lipid-lowering effects of BA administration have also been found in largemouth bass (Guo et al., 2020). They found a decrease in plasma levels of triglyceride, total cholesterol and non-esterified fatty acids, but not phospholipids as a result of BA supplementation. However, dietary BA supplementation did not impact on LDL-C and HDL-C, which are somewhat in agreement with a previous study in grass carp (Zhou et al., 2018). The supplementation with BA increased HDL-C and reduced TC, TG and LDL-C concentrations, which might be linked to its effects on lipid metabolism. In general, both GOT and GPT are the main indicators for evaluating liver function. Elevated levels of these two enzymes usually indicate degeneration, necrosis, and destruction of the liver due to cellular damage in fish (Zhai et al., 2016; Guo et al., 2020). The lower activities of serum GOT and GPT indicated that the BA supplementation could reduce the liver damage in European eel, which was in agreement with previously report of adequate dietary BA level in largemouth bass (Guo et al., 2020) and tilapia(Jiang et al., 2018), while Zhou et al. (2018) did not find decrease of those two enzymes in grass carp fed diets with high lipid level and $60 \mathrm{mg} / \mathrm{kg} \mathrm{BA}$

The Israeli Journal of Aquaculture - Bamidgeh • IJA.72.2020.1217104 
supplementation. BA are also known to be cytotoxic to hepatocytes, high dietary BA supplementation ( $1350 \mathrm{mg} / \mathrm{kg}$ diet) could cause the highest GOT and GPT activities with serious nuclear migration and vacuolization in hepatocytes of tilapia (Jiang et al., 2018). These differences might be attributed to different fish species, BA levels and dietary nutrient content.

Immune function is related to innate and adaptive immune components, such as ACP, AKP, LZM, C3 and immunoglobulins in fish (Peng et al., 2019; Guo et al., 2020). ACP is a typical lysosomal enzyme that kills and digests microbial pathogens. AKP is a kind of multifunctional enzyme in the immune defense system of fish, capable of promoting phagocytosis through modification of the pathogen surface molecules (Jin et al., 2019). The activity of LZM, an important index of innate immunity of fish, is considered as a defense barrier against bacterial pathogens (Zhai et al. 2017; Guo et al., 2020). IgM is one of two important classes of immunoglobulins and the only immunoglobulin class responding to antigenic challenge both in systemic and mucosal compartments in fish (Zhang et al., 2011). Complement system plays a crucial role in the innate response of fishes, it is an important link between innate and adaptive immunity in the immune system. $\mathrm{C} 3$ is the most important and central complement component (Fu et al., 2019). The present study clearly found that BA supplementation enhanced the immune function of intestine by promoting activities of AKP, ACP and LZM and the contents of IgM and C3. These results suggested that dietary BA supplementation could strengthen the serum immune function partially associated with increasing innate and adaptive immune components of fish. Similar results were found in studies of grass carp (Peng et al., 2019), black seabream (Jin et al., 2019), and largemouth bass fed diets with BA supplementation (Guo et al., 2020).

The growth performance of fish is strongly correlated with intestinal health, which partly relies on diversity and richness of the intestinal microbiota (Peng et al., 2019; Shi et al., 2020). The number of OTUs and Chao1 are usually used to evaluate the richness of bacteria species. And Shannon index is used as the indicator of bacteria species diversity. The high coverage index value indicates that the majority of intestinal bacteria may be identified (Huang et al., 2018; Lin et al., 2019; Shi et al., 2020). In the present trial, the relatively higher values of OTUs and Chao1 and lower values of Shannon index indicated that BA supplementation might increase richness and decrease diversity of the bacteria in intestine of growth retarded European eel. Similar results were reported in grass carp fed diet $60 \mathrm{mg} / \mathrm{kg}$ BA supplementation (Zhou et al., 2018).

LEfSe method is well known to aid biologists by suggesting biomarkers that explain most of the effects differentiating phenotypes in biomarker discovery comparative investigations (Segata et al., 2011). In the present trial, the enriched bacteria at genus level were obviously different among the three treatment groups, which was in accordance with previous results that indicated that BA affected growth and diversity of microbiota in the intestine (Islam et al., 2011; Zhou et al., 2018). In the control group, the bacteria from Microbacteriaceae family might be the potential pathogen (Giorgia et al., 2018). Results of studies with amino acidmetabolizing bacteria in small intestine indicated that bacteria belonging to the Clostridium and Escherichia-Shigella could play an important role in amino acid utilization in animals (Fan et al., 2017; Shi et al., 2020). The Lachnospiraceae_NK4A136_group had beneficial effect on the intestine health of European eels (Shi et al., 2020). Macellibacteroides was found to use hydrolysate of polysaccharides as substrate to produce more short chain fatty acids (He et al., 2019), the short chain fatty acids could affect the fish performance as well as physiological response through effects on the gastrointestinal tract of the animal or through direct effects on metabolism (Hoseinifar et al., 2016), the increasingly relative abundances of above bacteria caused by BA supplementation might have beneficial effects on nutritional metabolism and intestinal health, their functions in eel intestine should be confirmed in a further study. Edwardsiella and Plesiomonas are common bacterial pathogens in eel culture (He et al., 2020; Shi et al., 2020). The relative abundances of these two bacteria were higher in BA group I, while no intestine health problem was observed in the process cultivation and other results of present study. It indicated that the levels of relative abundances of Edwardsiella and Plesiomonas in intestine might not exert negative effects on intestinal health. Therefore, it might be concluded that BA supplementation might cause the changes of intestinal bacteria with increasing abundance of some probiotics bacteria as well as some pathogenic bacteria,

The Israeli Journal of Aquaculture - Bamidgeh • IJA.72.2020.1217104 
these results were similar with previous study in grass carp (Zhou et al., 2018). It was reported that BA might act as detergents to interact with bacterial membrane lipids thereby conferring potent antimicrobial properties, they can regulate gut microbial composition both directly and indirectly by activation of innate immune response genes in the small intestine (Inagaki et al., 2006; Di Ciaula et al., 2017). While the intestinal bacteria also play a major role in BA metabolism because they are responsible for the transformation of the primary $B A$ to the secondary BA. Therefore, host metabolism can be affected by both microbial modifications of BA and alterations in the composition of the microbiota (Inagaki et al., 2006; Di Ciaula et al., 2017; Kiriyama and Nochi, 2019). Further study is needed to investigate the detail mechanisms of BA modulating the intestinal microbiota of growth retarded eels.

In conclusion, this study demonstrated that $500 \mathrm{mg} / \mathrm{kg}$ BA supplementation in the diet could promote the growth performance with improvement of some digestive enzymes activities and regulation of serum biochemical parameters as well as intestinal microbiota of growth retarded European eels cultured in cement tanks.

\section{Acknowledgements}

This work was financially supported by China Agriculture Research System (CARS-46), Science and Technology Key Project of Fujian Province (2018N0020) and Open Fund of Engineering Research Center of the Modern Industry Technology for Eel, Ministry of Education (RE201904; RE202009) are gratefully acknowledged.

\section{References}

Adhami B., Amirkolaie A.K., Oraji H. and R.E. Kenari, 2017. Growth performance, nutrient digestibility and lipase activity in juvenile rainbow trout (Oncorhynchus mykiss) fed fat powder in diet containing emulsifiers (cholic acid and Tween-80). Aquacult. Nutr., 23:1153-1159. doi:10.1111/anu.12484

Buchinger T.J., Li W. and N.S. Johnson, 2014. Bile salts as semiochemicals in fish. Chem. Sen., 39:647. doi:10.1093/chemse/bju039

Di Ciaula A., Garruti G., Lunardi Baccetto R., Molina-Molina E., Bonfrate L., Wang D.Q.H. and P. Portincasa, 2017. Bile Acid Physiology. Ann. Hepatol., 16: S4-S14. doi: $10.5604 / 01.3001 .0010 .5493$

Ding T., Xu N., Liu Y., Du J., Xiang X., Xu D., Liu Q., Yin Z., Li J., Mai K. and Q. Ai, 2020. Effect of dietary bile acid (BA) on the growth performance, body composition, antioxidant responses and expression of lipid metabolism-related genes of juvenile large yellow croaker (Larimichthys crocea) fed high-lipid diets. Aquaculture, 518:734768. doi:10.1016/j.aquaculture.2019.734768

Du J., Xu H., Li S., Cai Z., Mai K. and Q. Ai, 2017. Effects of dietary chenodeoxycholic acid on growth performance, body composition and related gene expression in large yellow croaker (Larimichthys crocea) fed diets with high replacement of fish oil with soybean oil. Aquaculture, 479: 584-590. doi:10.1016/j.aquaculture.2017.06.023

Fan P., Liu P., Song P., Chen X. and X. Ma, 2017. Moderate dietary protein restriction alters the composition of gut microbiota and improves ileal barrier function in adult pig model. Sci. Rep., 7:43412. doi:10.1038/srep43412

Fu Y., Zhu C. and Q. Zhang, 2019. Molecular characterization and expression analysis of complement components C3 and C9 in largemouth bronze gudgeon (Coreius guichenoti) in response to Ichthyophthirius multifiliis infection. Aquaculture, 506:270-279. doi:10.1016/j.aquaculture.2019.03.046

Giorgia G., Elia C., Andrea P., Cinzia C., Stefania S., Ana R., Daniel M.L., Ike O. and C. Oliana, 2018. Effects of lactogen 13, a new probiotic preparation, on gut microbiota and endocrine signals controlling growth and appetite of Oreochromis niloticus juveniles. Microb. Ecol., 76:1063-1074. doi:10.1007/s00248-018-1177-1

Gu M., Bai N. and T.M. Kortner, 2017. Taurocholate supplementation attenuates the changes in growth performance, feed utilization, lipid digestion, liver abnormality and sterol metabolism 
in turbot (Scophthalmus maximus) fed high level of plant protein. Aquaculture, 468:597-604. doi:10.1016/j.aquaculture.2016.11.022

Guo J., Kuang W., Zhong Y., Zhou Y., Chen Y. and S. Lin, 2020. Effects of supplemental dietary bile acids on growth, liver function and immunity of juvenile largemouth bass ( Micropterus salmoides) fed high-starch diet. Fish. Shellfish. Immun., 97: 602-607. doi:10.1016/j.fsi.2019.12.087

He L., Wu L., Lin P., Zhai S., Guo S., Xiao Y. and Q. Wan, 2020. First expression and immunogenicity study of a novel trivalent outer membrane protein (OmpII-U-A) from Aeromonas hydrophila, Vibrio vulnificus and Edwardsiella anguillarum. Aquaculture, 519:734932. doi:10.1016/j.aquaculture.2020.734932

He Z., Tang C., Liu W., Ren Y., Guo Z., Zhou A., Wang L., Yang C. and A. Wang, 2019. Enhanced short-chain fatty acids production from waste activated sludge with alkaline followed by potassium ferrate treatment. Bioresour. Technol., 289:121642. doi:10.1016/j.biortech.2019.121642

Hoseinifar S.H., Sun Y.Z. and C.M. Caipang, 2016. Short-chain fatty acids as feed supplements for sustainable aquaculture: an updated view. Aquac. Res., 48(4):1380-1391. doi:10.1111/are.13239

Hou Y., Hou Y., Yao L., Chen S., Fan J. and L. Qian, 2019. Effects of chromium yeast, tributyrin and bile acid on growth performance, digestion and metabolism of Channa argus. Aquac. Res., 50:836-846. doi:10.1111/are.13954

Huang W., Cheng Z., Lei S., Liu L., Lv X., Chen L., Wu M., Wang C., Tian B. and Y. Song, 2018. Community composition, diversity, and metabolism of intestinal microbiota in cultivated European eel (Anguilla anguilla). Appl. Microbiol. Biot., 102(9):4143-4157. doi: $10.1007 / \mathrm{s} 00253-018-8885-9$

Huang Y., 2012. Comparison of digestive enzyme activities in normal and growth retarded Japanese eels (Anguilla japonics). Chinese. J. Anim. Nutr., 24(5):977-982. doi:10.3969/j.issn.1006-267x.2012.05.025

Inagaki T., Moschetta A., Lee Y.K., Peng L., Zhao G., Downes M., Yu R.T., Shelton J.M., Richardson J.A., Repa J.J., Mangelsdorf D.J. and S.A. Kliewer, 2006. Regulation of antibacterial defense in the small intestine by the nuclear bile acid receptor. P. Natl. Acad. Sci., 103:3920-3925. doi:10.1073/pnas.0509592103

Islam K.B.M.S., Fukiya S., Hagio M., Fujii N., Ishizuka S., Ooka T. and A. Yokota, 2011. Bile acid is a host factor that regulates the composition of the cecal microbiota in rats. Gastroenterology, 141:1773-1781. doi:10.1053/j.gastro.2011.07.046

Jacoby D.M.P., Casselman J.M., Crook V., DeLucia M., Ahn H., Kaifu K., Kurwie T., Sasal P., Silfvergrip A.M.C., Smith K.G., Uchida K., Walker A.M. and M.J. Gollock, 2015. Synergistic patterns of threat and the challenges facing global anguillid eel conservation. Glob. Ecol. Conserv., 4:321-333. doi:10.1016/j.gecco.2015.07.009

Jiang M., Wen H., Gou G.W., Liu T.L., Lu X. and D.F. Deng, 2018. Preliminary study to evaluate the effects of dietary bile acids on growth performance and lipid metabolism of juvenile genetically improved farmed tilapia (Oreochromis niloticus) fed plant ingredient-based diets. Aquacult. Nutr., 24: 1175-1183. doi:10.1111/anu.12656

Jin M., Pan T., Cheng X., Zhu T.T., Sun P., Zhou F., Ding X. and Q. Zhou, 2019. Effects of supplemental dietary L-carnitine and bile acids on growth performance, antioxidant and immune ability, histopathological changes and inflammatory response in juvenile black seabream (Acanthopagrus schlegelii) fed high-fat diet. Aquaculture, 504:199-209. doi:10.1016/j.aquaculture.2019.01.063

Kiriyama Y. and $\mathbf{H}$. Nochi, 2019. The biosynthesis, signaling, and neurological functions of bile acids. Biomole, 9(6):232. doi:10.3390/biom9060232

Lin M., Zeng C., Jia X., Zhai S., Li Z. and Y. Ma, 2019. The composition and structure of the intestinal microflora of Anguilla marmorata at different growth rates: a deep sequencing study. J. Appl. Microbiol., 126(5):1340-1352. doi:10.1111/jam.14174

Maita M., Tachiki H., Kaibara A., Itawaki R. and Y. Ikeda, 1996. Pharmacological effect of ursodeoxycholic acid in juvenile eel (Anguilla anguilla L.). Nippon Suisan Gakk.,62(1):129130. doi:10.2331/suisan.62.129 
Mukhopadhyay S. and U. Maitra, 2004. Chemistry and biology of bile acids. Curr. Sci. India., 87:1666-1683. doi:10.1073/pnas.0409058101

Nijman V., 2017. North Africa as a source for European eel following the 2010 EU CITES eel trade ban. Mar. Policy., 85 (11):133-137. doi:10.1016/j.marpol.2017.06.036

Peng X., Feng L., Jiang W., Wu P., Liu Y., Jiang J., Kuang S., Tang L. and X. Zhou, 2019. Supplementation exogenous bile acid improved growth and intestinal immune function associated with NF-kappa B and TOR signalling pathways in on-growing grass carp (Ctenopharyngodon idella): Enhancement the effect of protein-sparing by dietary lipid. Fish. Shellfish. immun., 92:552-569. doi:10.1016/j.fsi.2019.06.047

Ramírez-Pére O., Cruz-Ramon V., Chinchilla-Lopez P. and N. Mendez-Sanchez, 2017. The Role of the Gut Microbiota in Bile Acid Metabolism. Ann. Hepatol., 2017, 16(S1):21-26. doi: 10.5604/01.3001.0010.5494

Romański K.W., 2007. The role and mechanism of action of bile acids within the digestive system - bile acids in the liver and bile. Adv. Clin. Exp. Med., 16:793-799. doi:10.1007/9783-540-45456-4_43

Segata N., Izard J., Waldron L., Gevers D., Miropolsky L., Garrett W.S. and C. Huttenhower, 2011. Metagenomic biomarker discovery and explanation. Genome. Biol., 12(6):R60. doi:10.1186/gb-2011-12-6-r60

Shi Y., Ma D. and S. Zhai, 2020. Revealing the difference of intestinal microbiota composition of cultured European eels (Anguilla anguilla) with different growth rates. Isr. J. AquacultBamidgeh, AquacultureHub, IJA_72.2020.959575, 12 pages.

Staessen T.W.O., Verdegem M.C.J., Weththasinghe P. and J.W. Schrama, 2020. The effect of dietary non-starch polysaccharide level and bile acid supplementation on fat digestibility and the bile acid balance in rainbow trout (Oncorhynchus mykiss). Aquaculture, 523:735174. doi: $10.1016 / j$.aquaculture.2020.735174

Sun J., Wang J., Ma J., Li B., Hao T., Sun Y. and L. Zhang, 2014. Effects of dietary bile acids on growth, body composition and lipid metabolism of juvenile turbot (Scophthalmus Maximus) at different lipid levels. Oceanologia. Et. Limnologia. Sinica., 45(3):617-625. doi:10.11693/hyhz20140300092

Xiang X., Zeng B., Yang L., Zhou X., Chen J. and W. Wang, 2019. Effects of high-lipid diet supplemented with bile acid on growth performance, muscle nutritional component contents, digestive enzyme activities and serum biochemical indices of juvenile Schizothorax prenanti. Chinese. J. Anim. Nutr., 31(11): 5089-5099. doi:10.3969/j.issn.1006-267x.2019.11.024

Yamamoto T., Suzuki N., Furuita H., Sugita T., Tanaka N. and T. Goto, 2007. Supplemental effect of bile salts to soybean meal-based diet on growth and feed utilization of rainbow trout Oncorhynchus mykiss. Fisheries. Sci., 73(1), 123-131. doi:10.1111/j.14442906.2007.01310.x

Yu H., Zhang L., Chen P., Liang X., Cao A., Han J., Wu X., Zheng Y., Qin Y. and M. Xue, 2019. Dietary bile acids enhance growth, and alleviate hepatic fibrosis induced by a high starch diet via AKT/FOXO1 and CAMP/AMPK/SREBP1 pathway in Micropterus salmoides. Front. Physiol., 10:1430. doi:10.3389/fphys.2019.01430

Zhai S., Chen X. and M. Wang, 2017. Effects of different levels of dietary surfactin supplementation on intestinal morphology, and intestinal microflora of growth retarded marbled eel juveniles (Anguilla marmaorata). Isr. J. Aquacult-Bamidgeh, AquacultureHub, IJA_69.2017.1433, 7 pages.

Zhai S., Shi Q. and X. Chen, 2016. Effects of dietary surfactin supplementation on growth, digestive enzymes activities and antioxidant potential in intestine of growth retarded marbled eel (Anguilla marmorata) at elver stage..Isr. J. Aquacult-Bamidgeh, AquacultureHub, IJA_68.2016.1282, 7 pages.

Zhang Y., Salinas I. and J.O. Sunyer, 2011. Recent findings on the structure and function of teleost IgT. Fish. Shellfish. Immun., 31: 627-634. doi:10.1016/j.fsi.2011.03.021

Zhang C. and T.J. Hara, 2009. Lake char (Salvelinus namaycush) olfactory neurons are highly sensitive and specific to bile acids. J. Comp. Physiol. A., 195:203. doi:10.1007/s00359-0080399-y

Zheng Z., Zeng B., Xiang X., Zhou X., Chen J., Lv G, Zhu C., Li D. and S. Ren, 2016. Effects of bile acid supplemental level on growth performance, physical indices and body 
composition of juvenile Schizothorax prenanti. Chinese. J. Anim. Nutr.,28(8): 2423-2430. doi:10.3969/j.issn.1006-267x.2016.08.013

Zhou J., Chen H., Ji H., Shi X., Li X., Chen L., Du Z. and H. Yu, 2018. Effect of dietary bile acids on growth, body composition, lipid metabolism and microbiota in grass carp (Ctenopharyngodon idella). Aquacult. Nutr., 24:802-813. doi:10.1111/anu.12609

Zhou S., Liu Y., Liang H., Zhao L., Tian L., Yang H. and G. Liang, 2010. Effect of bile acids on growth and body composition of cobia (Rachycentron canadum). S. China. Fish. Sci., 6(4):20-25. doi: 10.3969/j.issn.1673-2227.2010.04.004 